\title{
Reflex vasomotor abnormalities in the hands of migrainous subjects
}

\author{
O. APPENZELLER, K. DAVISON, AND JOHN MARSHALL \\ From the Institute of Neurology and National Hospitals for Nervous Diseases, Queen Square, London
}

Many symptoms and signs of migraine can be explained by changes in the calibre of cerebral vessels (Wolff, 1948). Abnormalities in the size and a reduction in the amplitude of pulsation of extracranial vessels during intervals free of headache have been described (Wennerholm, 1961; Tunis and Wolff, 1953).

Anatomical variations from the normal adult pattern of the capillaries of the finger nail folds in migrainous subjects have also been found (Hauptmann, 1946). Because of these findings in extracranial vessels it was of interest to study vasomotor reflexes in the hand vessels of such patients during intervals free of headache. Kerslake and Cooper (1950) described vasodilatation in the hands of normal subjects in response to heating of the skin elsewhere. They showed that this increase in hand blood flow is dependent on neural afferents from the heated area. This is a reflex response different from the vasodilatation obtained with prolonged heating of the body, and depends on warm blood causing release of vasomotor tone (Pickering and Hess, 1933). This paper reports reflex responses observed in the blood flow in the hand of migrainous subjects.

\section{MATERIAL AND METHOD}

The experiments were performed on 10 patients with classical migraine during periods free of attacks. All suffered from periodic circumscribed headaches preceded by an aura, details of which are given in Table I. All those who presented themselves for follow-up to the outpatient department during this investigation and agreed to cooperate were included. Two subjects were in-patients admitted for investigation of their headaches. A summary of the relevant points of the patients studied is given in Table I. The patients were compared with 10 controls of whom five were in-patients with disorders unlikely to affect their vasomotor responses and five were normal volunteers (Table II). No subject had any special preparation and none was familiar with the procedure. All medication was suspended for 48 hours before the test. The experiments were performed during a period of warm weather, the subject resting for threequarters of an hour beforehand at an ambient temperature of $24^{\circ} \mathrm{C}$. to $26^{\circ} \mathrm{C}$. There was one observer in the room and silence was maintained apart from the noise of the apparatus which was monotonous. Most subjects fell asleep for short periods during the test.

The subjects lay comfortably on a bed clad only in underwear with the chest exposed. A heat cradle containing six 100 watt lamps was placed over the chest and the ends of the cradle were screened off by woollen blankets. This arrangement allowed the right hand to be placed in a water-filled venous occlusion plethysmograph at $32^{\circ} \mathrm{C}$. The arm was not exposed to radiation and was resting on sandbags. The procedure was similar to that described by Kerslake and Cooper (1950).

The chest was heated for 40 seconds. The collecting cuff of the plethysmograph was manually operated and inflation maintained for four seconds with a four-second interval between collecting periods. Five resting readings followed by five readings during the period of heating and five readings after the cradle was switched off constituted a run. Ten runs were recorded on each patient. Flows at corresponding times of the 10 runs were averaged. The runs were made at seven-minute intervals to allow the blood flow to settle to resting levels. Automatic cuff inflation for five seconds three times every minute was maintained between runs. Changes in hand blood flow in response to the application of iced water to the feet, a single deep breath, and mental arithmetic were also studied in nine migrainous patients and in all controls.

\section{RESULTS}

All controls had a rapid vasodilatation with a consequent increase in hand blood flow which was largest towards the end of the heating period and returned to resting levels within 30 seconds of switching off. These results were similar to the responses observed in normal subjects by Kerslake and Cooper (1950). Eight of the 10 patients with migraine did not have the expected vasodilatation (Table I, Fig. 1B, Fig. 2). There was no significant rise in hand blood flow during the 40 seconds' heating and some showed marked swings in flow during the period of irradiation of the chest. Two patients had a normal response comparable to that of our controls. The test was repeated on two other patients and on the second occasion there was again 

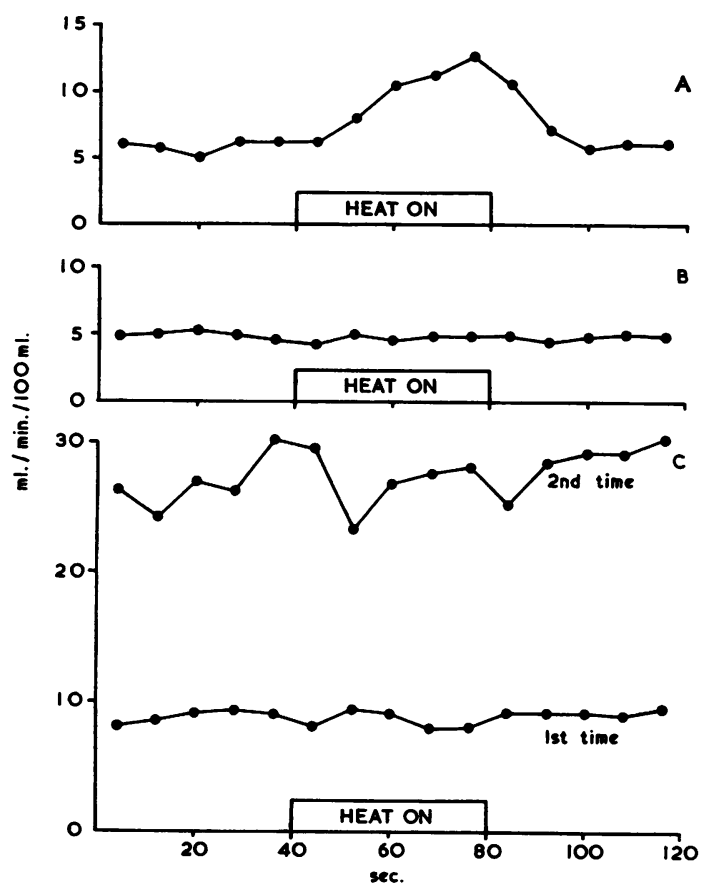

FIG. 1. A Typical result from a control.

B Typical result from a migrainous subject (no. 9).

C Results of two successive experiments on a migrainous subject (no. 10). no reflex response in these subjects (Table I, Fig. 1C). A statistical analysis of the results is shown in Tables I and II. The base line flow is the mean of the last two readings obtained before and the last two readings after heating. The response to trunk heating is the mean change in hand blood flow observed during the last 32 seconds of irradiation. The values obtained for each patient represent the mean of 10 runs. The results show that a significant vasodilatation was produced in all controls but in only two of the 10 migrainous subjects (nos. 2 and 6).

The mean pre- and post-heating flows in the patients with migraine and the controls do not differ significantly (pre-heating $P>0.4$; post-heating $\mathbf{P}>0.5$ ). The mean vasodilatation produced by means of a heat cradle was $3.9 \mathrm{ml} . / \mathrm{min} . / 100 \mathrm{ml}$. in the controls but only $0.8 \mathrm{ml} . / \mathrm{min} . / 100 \mathrm{ml}$. in the patients, the difference between the two groups being significant at the $1 \%$ level.

The application of iced cold water to the feet, taking a single deep breath, and doing mental arithmetic caused a marked fall in hand blood flow in the nine migrainous subjects tested and in all the controls.

\section{DISCUSSION}

Eight out of 10 patients with long-standing classical migraine failed to show the normal reflex vasodilata-
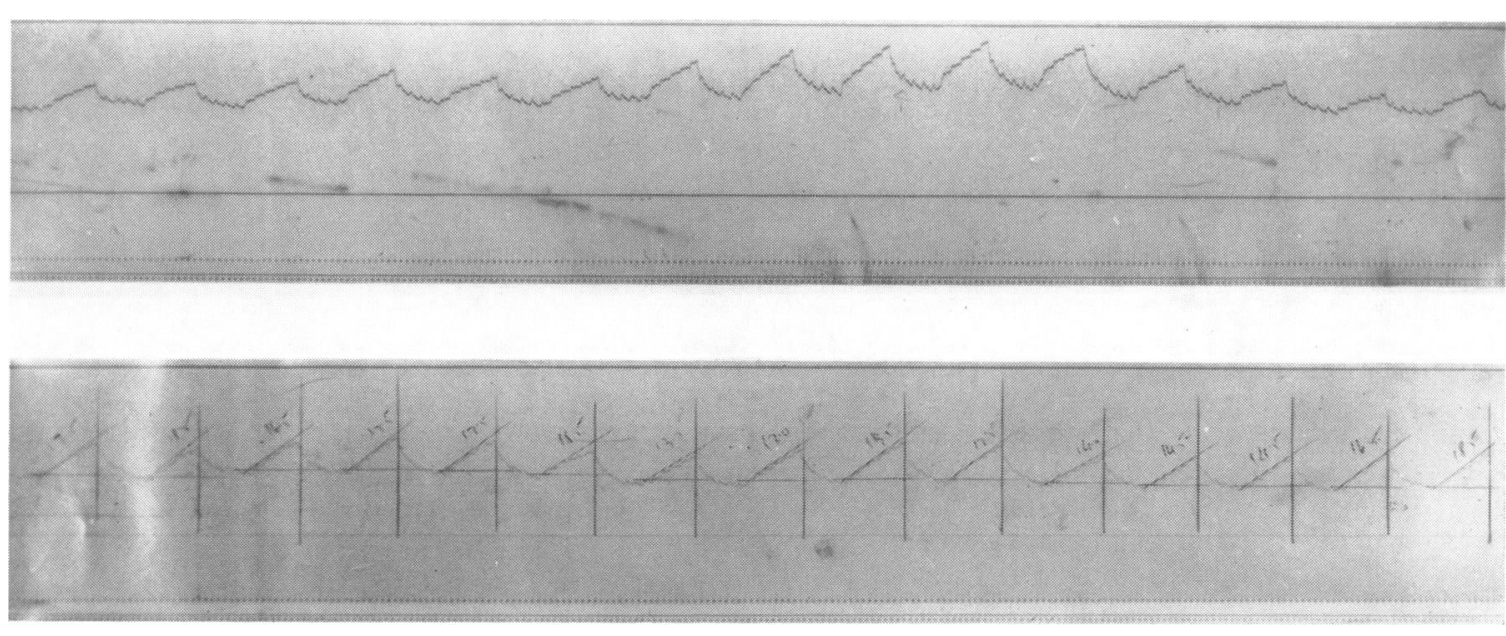

FIG. 2. Actual records from a normal control above and a migrainous subject below. Time marked $\frac{1}{2}$ second. Venous occlusion was maintained during four seconds with a four-second interval. Five baseline recordings followed by five recordings during the 40 seconds' heating of the trunk and five recordings after switching off the cradle are shown. These records constitute a run (see text). 
TABLE I

RESULTS IN 10 PATIENTS WITH MIGRAINE

\begin{tabular}{|c|c|c|c|c|c|c|c|c|}
\hline $\begin{array}{l}\text { Patient } \\
\text { No. }\end{array}$ & $\operatorname{Sex}$ & $\begin{array}{l}\text { Age } \\
\text { in } \\
\text { Years }\end{array}$ & $\begin{array}{l}\text { Family History } \\
\text { of Migraine }\end{array}$ & $\begin{array}{l}\text { Length of History } \\
\text { in Years }\end{array}$ & Type of Aura & $\begin{array}{l}\text { Basal Hand } \\
\text { Blood Flow } \\
\text { (ml./100 ml./min.) }\end{array}$ & $\begin{array}{l}\text { Response to } \\
\text { Trunk Heating } \\
\text { Mean } \pm \text { S.D. } \\
\text { (ml./100 ml./min.) }\end{array}$ & $\begin{array}{l}P \\
(t \text { test })\end{array}$ \\
\hline 1 & $\mathbf{M}$ & 53 & + & 40 & Visual & $10 \cdot 3$ & $+0.2 \pm 1.7$ & $>0.70$ \\
\hline 2 & $\mathbf{F}$ & 38 & + & 16 & Visual & $6 \cdot 5$ & $+2 \cdot 7 \pm 1 \cdot 7$ & $<0.001$ \\
\hline 3 & $\mathbf{F}$ & 31 & - & 6 & Visual & $11 \cdot 1$ & $-0.2 \pm 1.0$ & $>0.50$ \\
\hline 4 & $\mathbf{F}$ & 50 & - & 20 & Visual & $7 \cdot 6$ & $-0.3 \pm 0.9$ & $>0.30$ \\
\hline 5 & $\mathbf{F}$ & 37 & + & 30 & Visual and sensory & $9 \cdot 5$ & $+0.1 \pm 1.5$ & $>0.80$ \\
\hline 6 & $\mathbf{F}$ & 57 & + & 40 & Visual and sensory & 10.4 & $+1.6 \pm 1.9$ & 0.05 \\
\hline 7 & $\mathbf{M}$ & 17 & - & 13 & Sensory & $11 \cdot 2$ & $+0 \cdot 1 \pm 1 \cdot 7$ & $>0.90$ \\
\hline 8 & $\mathbf{M}$ & 54 & - & 10 & Visual & $5 \cdot 2$ & $+0.5 \pm 0.7$ & $>0.05$ \\
\hline 9 & $\mathbf{M}$ & 44 & + & 25 & Visual & a) $5 \cdot 2$ & $+0.3 \pm 0.6$ & $>0 \cdot 10$ \\
\hline & & & & & Sensory and motor & b) 11.6 & $0 \pm 2 \cdot 0$ & - \\
\hline 10 & $\mathbf{F}$ & 52 & - & 17 & Visual & $\begin{array}{l}\text { a) } 10 \cdot 2 \\
\text { b) } 29 \cdot 4\end{array}$ & $\begin{array}{l}-0.4 \pm 1.0 \\
-2.7 \pm 5.0\end{array}$ & $\begin{array}{l}>0.3 \\
>0.10\end{array}$ \\
\hline \multicolumn{6}{|c|}{ Mean of all patients } & $8 \cdot 4$ & $+0.8 \pm 1.3$ & - \\
\hline
\end{tabular}

TABLE II

RESULTS IN 10 CONTROL SUBJECTS

\begin{tabular}{|c|c|c|c|c|c|c|}
\hline Control No. & Sex & $\begin{array}{l}\text { Age in } \\
\text { Years }\end{array}$ & Diagnosis & $\begin{array}{l}\text { Basal Hand } \\
\text { Blood Flow } \\
\text { (ml./100 ml./min.) }\end{array}$ & $\begin{array}{l}\text { Response to Trunk } \\
\text { Heating Mean } \pm S . D . \\
(\mathrm{ml} . / 100 \mathrm{ml} . / \mathrm{min} .)\end{array}$ & $\begin{array}{l}P \\
(t \text { test })\end{array}$ \\
\hline $\begin{array}{r}1 \\
2 \\
3 \\
4 \\
5 \\
6 \\
7 \\
8 \\
9 \\
10\end{array}$ & $\begin{array}{l}\mathbf{M} \\
\mathbf{F} \\
\mathbf{M} \\
\mathbf{M} \\
\mathbf{M} \\
\mathbf{M} \\
\mathbf{M} \\
\mathbf{M} \\
\mathbf{M} \\
\mathbf{M}\end{array}$ & $\begin{array}{l}49 \\
50 \\
21 \\
55 \\
49 \\
32 \\
33 \\
35 \\
54 \\
30\end{array}$ & $\begin{array}{l}\text { Sinusitis } \\
\text { Cerebrovascular disease } \\
\text { Cerebral tumour } \\
\text { Prolapsed disc } \\
\text { Recovered Guillain-Barré syndrome } \\
\text { Healthy volunteer } \\
\text { Healthy volunteer } \\
\text { Healthy volunteer } \\
\text { Healthy volunteer } \\
\text { Healthy volunteer }\end{array}$ & $\begin{array}{r}7 \cdot 8 \\
6 \cdot 9 \\
7 \cdot 7 \\
4 \cdot 5 \\
7 \cdot 7 \\
4 \cdot 6 \\
12 \cdot 1 \\
11 \cdot 9 \\
6 \cdot 0 \\
14 \cdot 3\end{array}$ & $\begin{array}{l}+2 \cdot 2 \pm 1 \cdot 1 \\
+6 \cdot 8 \pm 2 \cdot 1 \\
+3 \cdot 2 \pm 1 \cdot 8 \\
+1 \cdot 1 \pm 0 \cdot 8 \\
+2 \cdot 3 \pm 2 \cdot 3 \\
+2 \cdot 9 \pm 1 \cdot 0 \\
+4 \cdot 2 \pm 2 \cdot 0 \\
+4 \cdot 5 \pm 1 \cdot 7 \\
+1 \cdot 1 \pm 0 \cdot 5 \\
+5 \cdot 6 \pm 2 \cdot 6\end{array}$ & $\begin{array}{l}<0.05 \\
<0.001 \\
<0.02 \\
<0.02 \\
<0.05 \\
<0.001 \\
<0.001 \\
<0.02 \\
<0.02 \\
<0.001\end{array}$ \\
\hline \multicolumn{4}{|c|}{ Mean of all subjects } & $7 \cdot 7$ & $+3.9 \pm 1.9$ & - \\
\hline
\end{tabular}

tion in the hand in response to 40 seconds' heating of the skin elsewhere.

It is unlikely that the circumstances under which the reflex vasomotor changes were observed prevented the vasodilatation in the patients because both they and the controls were tested in an identical environment. The high ambient temperatures ensured that the resting blood flows were fairly large in most instances and it is therefore not likely that vasodilatation was absent because of small initial flows. Lack of responsiveness is sometimes seen when indirect vasodilatation is produced by prolonged heating in lower environmental temperatures (Redisch, Sheckman, and Steele, 1952), a reflex which on the afferent side is dependent on the warm blood reaching higher centres and causing release of vasomotor tone (Pickering and Hess, 1933).

Maximal vasodilatation which may have been produced by the high ambient temperatures also cannot be held responsible for the lack of reflex increase in hand blood flow. This is shown by the patients tested twice who, despite fairly large resting flows on the first occasion, had very much larger preheating blood flows when tested subsequently
(Fig. 1C). Furthermore, vasodilatation in the hand is only about one-third complete at an ambient temperature of $28^{\circ} \mathrm{C}$. (Forster, Ferris, and Day, 1946), whereas our experiments were performed at temperatures ranging from $24^{\circ} \mathrm{C}$. to $26^{\circ} \mathrm{C}$.

It could be argued that the conditions of the experiment caused emotional vasoconstriction and thus prevented the normal reflex vasodilatation in the hand (Ackner, 1956). Neither patients nor controls had special preparation and they were not used to the procedure. Furthermore, the two migrainous subjects tested again when they were more familiar with the procedure did not show a normal reflex response on the second occasion three months later. In addition the basal flows of patients and controls were not significantly different, showing that vasoconstriction in the patients could not have prevented the normal vasodilator response.

It is possible that ergot alkaloids could have altered the reactivity of the hand vessels in these patients. All medication was therefore suspended for 48 hours before the test and none of the migrainous subjects showed signs of chronic ergot poisoning. One patient had not had the drug at all 
and another had taken it only very sporadically and in small doses some months previously, yet both these subjects failed to react normally to heating. The two patients with normal responses had been taking the drug for a long time. It seems likely, therefore, that the lack of normal reflex vasodilatation in response to 40 seconds' heating of the chest in our eight patients was due to abnormalities in vasomotor reactivity of the hand vessels coexisting with their disease.

Campbell, Hay, and Tonks (1951) showed that there is a continuously abnormal sodium metabolism in patients with migraine, and there is some evidence of alterations in the peripheral arterioles in migraine. Thus Walker (1959) showed that migrainous subjects had a significantly higher blood pressure than a control group and that the incidence of migraine in patients over 50 with essential hypertension rose with the level of the blood pressure. Hypertension can be influenced by lowering the dietary intake of sodium and it may be that the changes in sodium metabolism in migraine could account for the abnormal vascular response described.

Alterations in serotonin metabolism in migrainous subjects have been reported (Ostfeld 1960; Sicuteri, Testi, and Anselmi, 1961). Serotonin and its breakdown products are vasoactive substances and it is conceivable that these could alter the normal reactivity of the vessels and thus influence reflex changes in blood flow.

The neural pathways necessary for reflex vasodilatation in the hand were presumably intact in our patients. The vasoconstrictor responses to cold, a single deep breath, and mental arithmetic were preserved and on clinical testing there was normal cutaneous sensibility in the heated area. It is of course possible that the failure to respond is a manifestation of a functional derangement of higher structures which may be concerned in this reflex. This could well be related to the vegetative abnormalities sometimes associated with migrainous headaches such as thirst, hunger, and sleepiness (Wolff, 1948).

The relation of the lack of reflex vasodilatation in the hands of some migrainous subjects to the symptoms of the disorder remains, however, obscure, and it may be postulated that it reflects a generalized abnormality of the blood vessels or their neural control which is continuously present in these patients.

\section{SUMMARY}

Reflex vasodilatation in the hand in response to 40 seconds' heating of the chest was tested in 10 migrainous subjects and 10 controls. Eight of the 10 patients with migraine failed to respond normally with an increase in hand blood flow. All controls had a significant vasodilatation. It is concluded that this provides evidence of a persisting abnormality in the control of blood flow through the hands of some migrainous subjects.

This work was done during the tenure of a postgraduate training fellowship in medicine from the University of Sydney by $O$. Appenzeller. Our thanks are due to the Nuffield Foundation for the provision of the apparatus.

\section{REFERENCES}

Ackner, B. (1956). J. psychosom. Res., 1, 21.

Campbell, D. A., Hay, K. M., and Tonks, E. M. (1951). Brit. med. J. 2, 1424.

Forster, R. E., II, Ferris, B. G., Jr., and Day, R. (1946). Amer. J. Physiol., 146, 600.

Hauptmann, A. (1946). Arch. Neurol. Psychiat. (Chicago), 56, 631. Kerslake, D. McK., and Cooper, K. E. (1950). Clin. Sci., 9, 31.

Ostfeld, A. M. (1960). J. Amer. med. Ass., 174, 1188.

Pickering, G. W., and Hess, W. (1933). Clin. Sci., 1, 213.

Redisch, W. E., Sheckman, E., and Steele, J. M. (1952). Circulation, $6,862$.

Sicuteri, F., Testi, A., and Anselmi, B. (1961). Int. Arch. Allergy, 19, 55.

Tunis, M. M., and Wolff, H. G.(1953). A.M.A. Arch. Neurol. Psychiat., $70,551$.

Walker, C. H. (1959). Brit. med. J., 2, 1430.

Wennerholm, M. (1961). Acta med. scand., 169, 131.

Wolff, H. G. (1948). Headache and Other Head Pain. Oxford University Press, New York. 